\title{
METHODOLOGICAL APPROACHES TO ASSESSMENT OF THE ACTIVITY OF THE GENERAL PRACTITIONER
}

\author{
Adolf Alakidi ${ }^{1}$, Vanina Mihaylova ${ }^{2}, 4$, Kristina Kilova ${ }^{3}$, Mariana Liochkova ${ }^{4}$ \\ Dimitar Shopov ${ }^{5}$ \\ 1) Department of Hygiene, Ecomedicine and Nutrition, Faculty of Medicine, \\ Medical University of Sofia, Bulgaria \\ 2) Department of Physiotherapy, Faculty of Public Health, Medical University \\ of Sofia, Bulgaria. \\ 3) Department of Medical Informatics, Biostatistics and E-learning, Faculty of \\ Public Health, Medical University of Plovdiv, Bulgaria. \\ 4) Department of Healthcare Management, Faculty of Public Health, Medical \\ University of Plovdiv, Bulgaria. \\ 5) Department Health Management and Economy of Health, Faculty of Public \\ Health, Medical University, Plovdiv, Bulgaria.
}

\begin{abstract}
After the launching of the health reform in the sphere of primary medical aid and a comparatively successful 20years' accomplishment, a need has arisen for an update of the medical standards ratifying the activity of the general medical practice (2011). The study of the work of the general practitioner in an ergonomic aspect requires the construction of a reliable complex of methodological studies providing a realistic assessment of the organization of the working process and of basic psycho-physical functions in the daily and weekly dynamics, carried out on the background of a dominant attachment of the physician to the chosen area of expertise.

The basic approaches for determination of the structure and expenses of the working time, or the efficiency coefficient (EC) respectively and intensity of labour involve the photochronometric- and the method of linear timing (also tracing the synchronization of the activity of the medical team); the spatial timing measuring the working trajectories, evidencing the degree of provision of functional working equipment and the objective conditions of labour. Sociological studies provide data on the style of communication with the patient and the occurrence of dilemmas of bioethical nature, as well as the strategies for their overcoming; sanitary and hygienic conditions of the working environment and their observation in accordance with the required criteria and indicators.

The methodologies enable objective assessment of the workload and structure of the physician's working time and the resulting fatigue. Preconditions are created for the implementation of optimal organizational and technological operations in the provision of medical services, aiming to increase in the efficiency of the working process, and establishment of a physiological regime of labour in the general medical practice within the framework of the effective legislation.
\end{abstract}

Keywords: general practitioner, working process, efficiency coefficient, working capacity, objective conditions of labour,
The health status of the population is directly dependent on the functioning of the primary medical aid structures. Within this scope, the key role belongs to the general medical practice, the leading figure being the general practitioner, whose main activity covers standards as specific measuring of the quality of their individual work and the conditions for its accomplishment [1]. Upon their creation, the established approach in qualitology: "structure-process - result" was used [2].

The positive, and also some negative transformations and reflections of the health reform (1999) on the preceding/original but not completely comparable model of the sectional principle of outpatient's services, are subject to further studies. Additional and in-depth analysis needs to be done, especially in the "result" part, and more specifically of the originating criteria and indicators in the direction of update; some corrections of the requirements for observation of the physiological regime of labour also need to be made (1999) [3].

The current approaches are mostly directed towards studying of the patients' satisfaction, as a sensitive quality criterion for the work performed in the practices of general medicine $[4,5,6,7,8,9,10]$.

Studies related to the workload, structure and expenses of working time by elements of the working process; good teamwork and synchronization of the activities of the medical team; keeping track of the processes of working capacity and fatigue in the dynamics of the working day and weak; the motivation and degree of satisfaction and devotion to the work; the occurrence of bioethical problems and their overcoming, remain in the periphery and are not sufficiently represented, probably due to their labour intensity [11].

The present work set up an objective to substantiate the necessity and mark out the essence and technology 
of conducting a complex of objective methodological studies, contributing to a trustworthy assessment of the GP's labour depending on the working regime, the subjective labour conditions, sanitary and hygienic factors of the environment, individual psycho-physiological specifications and preferences of the specialist in general medicine.

Studying the budget and the working hours' structure by means of time studies, measuring the amount of the time consumption by elements of the working process proves to be the main method of objective assessment of the general practitioner's labour (Table 1). The time studies are carried out by measurement of all, without exception, costs of the working time within the visit of one patient. The approach enables consistency and repeatability of the separate labour operations, as well as the establish- ment of extrinsic functions, outlining of non-production costs of working time.

For the correct measurement of the duration of a labour operation, its boundaries should be established by determining its fixing points - through differentiation of the moments of the beginning and end of each working element, i.e. it must have an initial and final fixing point. The final fixing point for a certain activity must coincide with the initial fixing point of the following activity [12]. A time check or a stopwatch is used. The data from the time-study are entered on a sheet/photochronometric map, fixing the sequence and name of the working operations and the consumption of time necessary for their implementation, applying the time of the beginning of each labour operation, as well as the completion of the previous one [13].

Tabl. 1. Time-studying map

\begin{tabular}{|c|c|c|c|c|c|}
\hline \multicolumn{6}{|c|}{ Time-studying map №........... } \\
\hline \multicolumn{3}{|l|}{ Date: } & \multicolumn{3}{|c|}{\begin{tabular}{l|l} 
Time checker: (full name) \\
\end{tabular}} \\
\hline \multicolumn{6}{|c|}{ Day of the week: } \\
\hline \multicolumn{6}{|c|}{ From $\ldots \ldots \ldots \ldots \ldots \ldots \ldots \ldots \ldots$ to $\ldots \ldots \ldots \ldots \ldots \ldots \ldots \ldots$ (hours) } \\
\hline \multicolumn{6}{|c|}{ Of (full name) } \\
\hline \multicolumn{6}{|c|}{ Age: $\quad$ years old } \\
\hline \multicolumn{3}{|c|}{ Working at } & \multicolumn{3}{|c|}{ (name of establishment) } \\
\hline \multicolumn{6}{|c|}{ Specialty } \\
\hline \multicolumn{6}{|c|}{ Total length of service as a physician } \\
\hline \multicolumn{6}{|c|}{ Length of service in the principal area } \\
\hline \multicolumn{6}{|c|}{ The office functions with $\quad$ nurses (number) } \\
\hline № & Rate frequency & Type of visit & $\begin{array}{c}\text { Type of activity } \\
\text { (code) }\end{array}$ & $\begin{array}{l}\text { Duration } \\
\text { (seconds) }\end{array}$ & Diagnosis \\
\hline
\end{tabular}

The monitored GP, on the other side, must have enough length of service and qualification. The necessary number of time measurements should ensure trustworthy representative data on the costs of working time for each labour operation [14]. Everything is based on an established qualification scheme, illustrating the elements of the working process within the framework of the outpatient's checkup, which is reduced to: main activity, supplementary activity, documentation work, other activity, official conversations, personal and free time [13]. The main activity covers: anamnesis and a number of diagnostic manipulations contributing to the diagnose, physical checkup, clarifications, advice, other activities, talking to the medical staff, literature references. The structure of the working time by elements of the labour process is reduced to the following: remedial and diagnostic activity - case history, physical checkup, advice, manipulation, preparatory activity (on the level and below the level of the physician's qualification), written works (on the level and below the level of the physician's qualification); time not connected with the immediate services rendered to the patients - administrative work, meetings, participation in committees, personal time, "interval pause" (periods of time in the ex- pectation of the patient); "idle time" (e.g. waiting, taking off/putting on patients' clothes); irrational activity (e.g. putting the desk in order, surfing the Internet, personal talks, including phone talks, distribution and supply of consumables, etc.) $[14,15]$. The written work (at the physician's level), with certain conventionality, includes drawing upstaged diagnoses, issuing patient's charts for temporary incapacity for work, writing prescriptions and referrals to a specialist, prescription of medical examinations, providing information to the health fund, etc., which the physician most often dictates to the nurse or uses a computer himself. While for facilitation reasons in the 1970s for this purpose the recommended devices included stamps, templates, cassette recorders, currently GPs, using the office equipped with a computer, are able to carry out this activity on their own. It turns out that the availability of a computer reduces the part of time designated for communication with the patient. A probable but not studied reason is the more difficult coping of the elderly physicians with the contemporary technologies; the remark "I think when I write" is very common. Domestic visits, including all elements, are an irrevocable and significant part of the GP's activity. 
The irrational activity, together with the "idle time" and the personal time, are the main and most significant source of reserve time for an increase in the physician's labour efficiency in the general practice. Clarification and subsequent elimination of the causes for irrationally used working time is a precondition for redistribution of the functional obligations, the introduction of technological improvements, adequately organized procedures directed towards optimization of the activity in the general medical practice. The methodology of the photochronometry enables assessment of the workload with a view to the improvement of the physician's activity in the relevant area of medical expertise, in compliance with the effective statutory and legal requirements.

The efficiency is taken as an index of the usefulness of the physician's labour in the general practice. It expresses the percentage relation of the activity requiring the level of the physician's qualification towards the whole time for outpatient's checkup/consultation. The high relative share of administrative activity in the total working time is a factor significantly lowering the efficiency of the physician's activity. Eliminating from the whole working time constituting $100 \%$, the personal, idle time and the interval pauses, the so-called "compaction" or intensity of the working time is obtained. Its high value not always means a rational organization of the working process and is often a precondition for the occurrence of errors in the physician's work.

It is worth noting that a study of the working time of the general practitioners in Manchester (Great Britain) was carried out even in the period 1938-39 by Bradford Hill and was published in 1951 [16, 17]. It traces basically the weekly workload with visits and the higher workload of the elderly physicians with domestic visits compared with the younger ones, preferring consultations held in the office. The average time set aside for domestic visit is reported within a 5.5 and 7-days' working week with average weekly time consumption of 45-50 hours. A large part of the physicians are fully on call - they seldom spend 4-4.5 hours "in a face to face contact", almost always during home visits. The graphic images illustrate data on the average expense of time for home visits and for the time envisaged for consultation, in the general medical practice in Denmark [18].

Communication with the patient is a significant part of the main activity, and for the general practitioner, it has a leading role and is his primary function. In his daily activity, the general practitioner is in a situation of permanent communication, with positive and not exclusively negative effects; it is unique in its essence. Communication not only supplements his professional competence but is considered its "core" [6], a building component which has a significant contribution not only to diagnostics but also to the therapeutic approach, mostly towards the patient's personality.

For the period 1952-1989 in Great Britain, there is a tendency for a sharp increase in the time for communication between the physician and the patient. One of the reasons is the increase in the number of GPs, which has led to a decrease in the number of patients in the general medical practice. Another cause is the change in the concept of the physician-patient relationship. From the initially traditional understanding of the paternalistic model, where the patient assumes passively the directions and liability for them from the physician, and the later liberalization of the model into partnership [19]. This so desired form of communication is almost never practiced (especially in Bulgaria), as it takes more time and is too complicated in its essence.

It is a well-known cliché that women like talking more and with more pleasure than men. The problem has been discussed in a separate study. While for the male physicians, the average daily spending of time for talks with the patient is $75 \mathrm{~min}$., for the female physicians, it is $80 \mathrm{~min}-$ utes. Therefore, for the male physician, the daily spending of time is $4,4 \mathrm{~min}$., and for the female physicians -4.38 , i.e. over half a minute more. Other studies show the opposite results. Rother et al. (1999) found out that the male gynecologists talk to their patients more than the female gynecologists. The same authors also state that the female gynecologists engage in their longer conversations in a partnership style of behavior. Moreover, they try to share with their patient's psycho-social information and emotionally more significant topics, and there is a relation between the professional experience and age of the physician and the duration of the conversation. The impact of the professional experience and gender on the physicians' satisfaction is also treated [20].

The spiritual structure of the physician, expressed in his verbal and non-verbal behavior, has a direct impact on the patient and is directed towards: finding and correcting the patient's weaknesses caused by the suffering; preservation of the dignity damaged by the disease; desire not to humiliate and betray the patient, to ensure equality in his relationships with the patient - preconditions for his efficient management. The solid knowledge of GP in the sphere of management, supported by a high level of competencies and skills in the field of medicine and improved through education and training of the communication skills, ensure coping with $90 \%$ of the problems of the patients who have visited his office. It is considered the fact that the information presented by a physician with good communication skills is more reliable and provides a more trustworthy and timely diagnosis in the emotional space managed by him.

Due to unknown reasons, the abbreviation GP/FD (family doctor) dropped out in the second part, probably because the separate family members could turn to/choose different Gps. It is well known that the family doctor has known the family for decades. In the process of their interaction, simultaneous aging occurs. The events in life, crises, tension, illnesses between the births and the deaths are accompanied by the presence of the doctor. The knowledge is complete - in good and in bad days. Along with this, the family doctor must penetrate in the atmosphere of the family, to study its "language". Without this, he won't be able to establish contact with it, i.e. the family doctor must be competent enough to carry out this communication [21].

The degree of synchronization in the activity of the medical team involves not only the parallel performance of one and the same activity by the physician and the nurse but most of all - the optimal allocation of the working operations, the coordination and good teamwork between the 
members of the team.

For determination of the degree of synchronization in the work of the medical team, the most appropriate proves to be the method of linear timing developed by $M$. Liochkova (2002) [22]. The average duration of the elements of the working process and the structure of the outpatient's visit are tracked down. The essence of the method is in the simultaneous time study of the working elements of the physician-nurse team during the outpatient's examination. The study is performed by one observer, entering the activities carried out by the different members of the team for one and the same time interval. The results of the observation are entered into an original form for synchronous graphic register of the time consumption (Table 2). The time study may be carried out by students from the program of Healthcare management during seminars as a research task, preceded by a theoretical and discussion part and a role-play in small groups.

Tabl. 2. Linear timing map

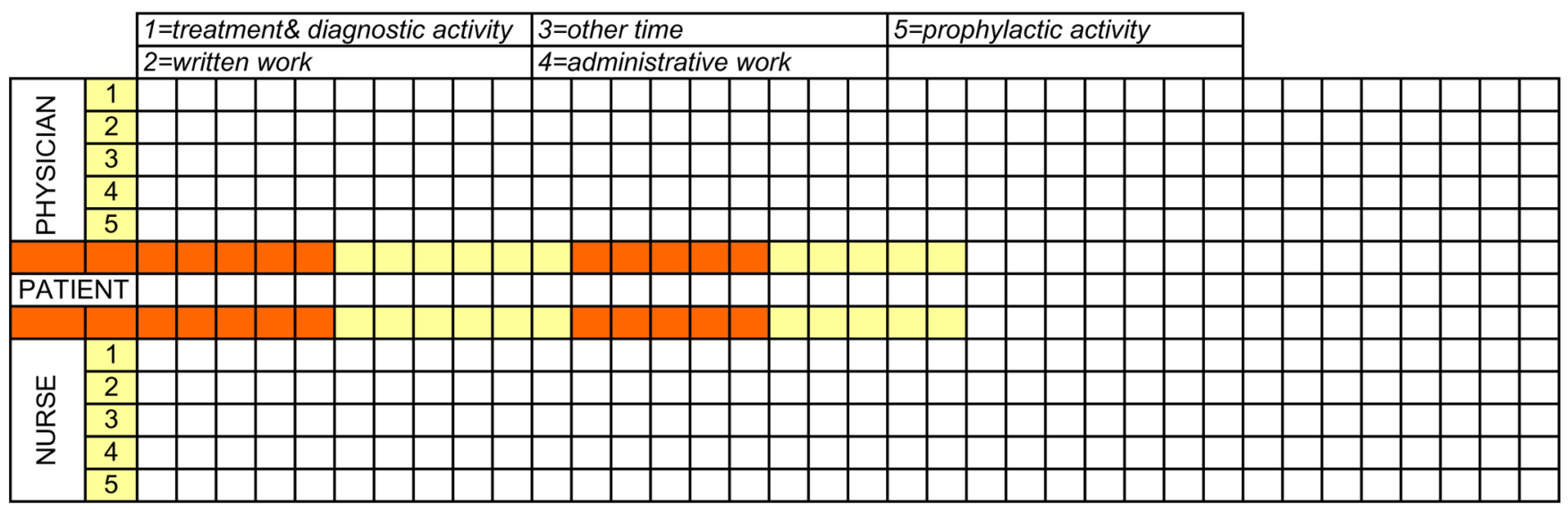

The left part of the chart represents the concentrated elements of the working process, using the digital designation of the accepted grouping of the main types of activities. The horizontal lines fix the duration of the work done - parallel for the physician and the nurse. Each division from the graphic image corresponds to 15 seconds, which enables working with the precision of the registration up to 5 seconds. At the same time, the patient's stay is marked by an uninterrupted line, on which the diagnosis is marked, along with the time of his entry and leaving of the office - with vertical lines. The parallel activities performed by the team members during the interval pause are also registered by an uninterrupted line opposite the patient's stay. A stopwatch is used. With the help of the linear timing method, the parallel and synchronous activity between the separate members of the working team is tracked down, and there is an opportunity for determination of the optimal ratio between them. The approach reports the functional obligations and the optimal means of simultaneous performance of the activities, which is a precondition for the increase in the efficiency of the medical labour under ambulatory conditions.

The working postures and working trajectories are some of the most important subjects of the ergonomic studies. From the point of view of the ergonomic system of the medical labour, the working postures are regarded as a key moment in the functioning of the system's components and more specifically, as an interim element in the relationship of the "physician-patient" and "physician - objective labour conditions" units (Kolarova Z.I, 1976).

With the help of the timing and photo registration, the static and dynamic components, as well as the static working postures in the GP's activity, are reported [23]. The postures "sitting" and "straight" are determined as main static elements and "bent" as compulsory. The micro-movements inside the office and the macro movements outside the office are registered as dynamic elements.

The ratio between the components of the static load, or the working postures respectively, is established using the timing method; through time studies and photo registration, the specific working postures are fixed, enabling determination of their duration and structure within the static loading in the course of the working day (Tables 3).

Tabl. 3. Timing map of the working postures

\begin{tabular}{|l|l|}
\hline \multicolumn{2}{|l|}{ Timing map of the working postures No. } \\
\hline Working postures & Time (minutes) \\
\hline Straight & \\
\hline Sitting & \\
\hline Bent & \\
\hline Walking & \\
\hline
\end{tabular}

The functionality of the working posture shows its correspondence to the activity which is performed when taking such posture. So the "straight" posture and the dynamic elements usually occupy a higher relative share, while "sitting" and "bent" - lower than the required from the activities for the performance of those two postures. The discrepancy between the working postures and the relative share of the elements requiring an adequate posture, show incomplete introduction and use of the facilities and apparatuses complying with the ergonomic requirements, and organizational deficiencies in the GP's work. 
Along with the study of the working postures in the aspect of the ergonomic studies, the specification of the general motive activity of the persons performing labour operations in the specific conditions of the environment is also very important. On a previously drawn scale scheme of the office (office block), the physician's and nurse's so- called working routes/trajectories are reflected (number and duration) within an outpatient's visit (chart 1). Using our method of "spatial timing", the following is registered: movements inside the office and to adjacent/related premises; direction from one object to another; going outside the office - total number and duration.

Chart 1. Work trajectories of the team in the practice of general medicine

\section{Doctor's office}

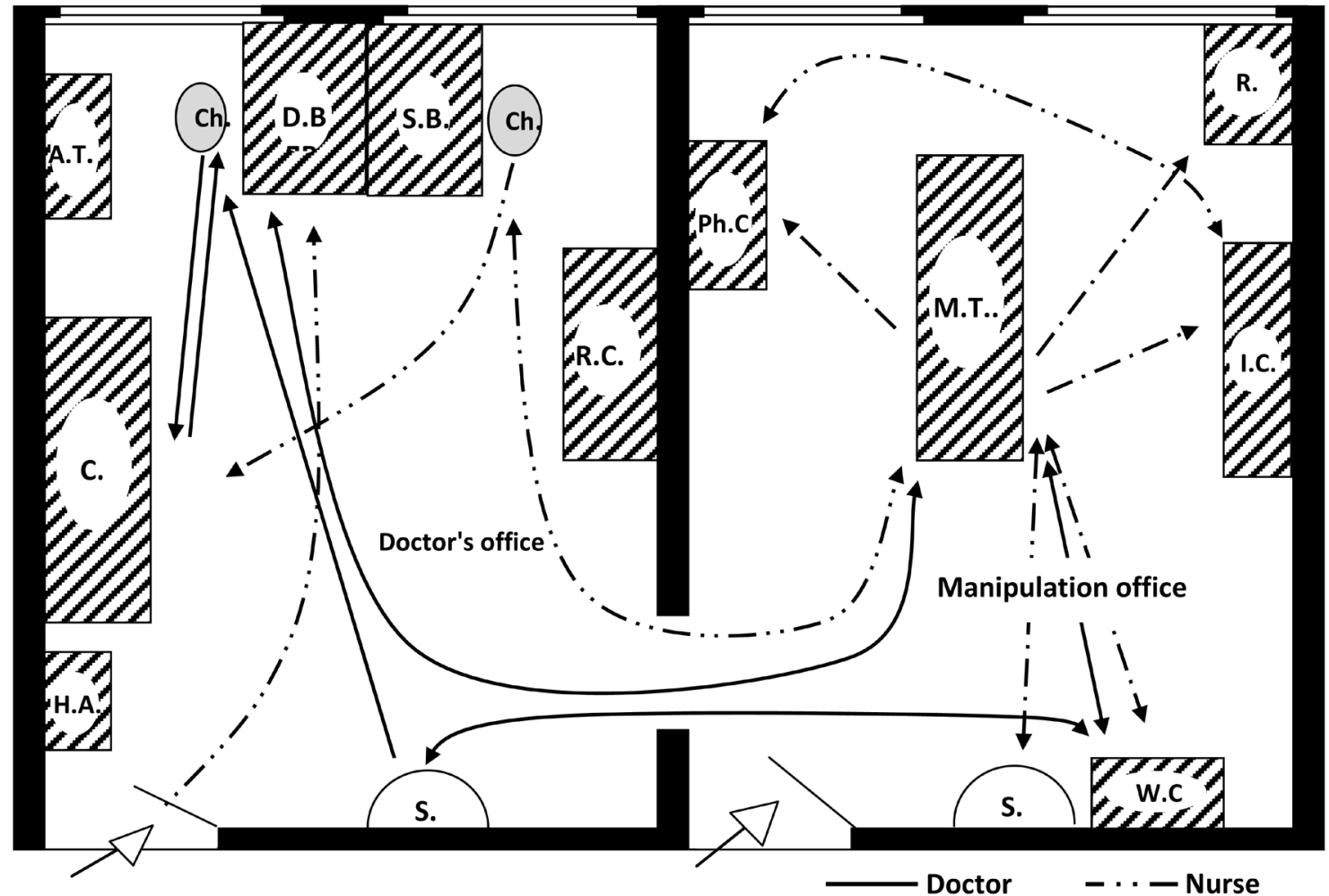

Legend: A.T. - AuxiliaryTable; C - Couch; S - Sink; Ph. C - Pharmacycommode; M.T. - Manipulationtable; D.B. - Doctor'sbureau; S.B. - Sister, bureau; H.A. - Heatingappliance; R.C. - Recordcommode; I.C. - Instrumentalcommode; Ch. - Chair; WC - Waste Container; R - Refrigerator;

The frequency of turning of the separate team members to some major objects in the office or the Diagnostic and Consulting Centre (DCC) illustrates the relation of the nature of the motive activity depending on the objective conditions of the environment.

The data give the opportunity to gain knowledge and make an assessment of the motive coordination in the activity of the medical team, and the rational organization of the working process within the envisaged territorial space.

The structure of the working trajectories illustrated on the chart given as an example, show their straightforwardness and non-straightforwardness, evidencing observation of the ergonomic requirements for the equipment and furnishing with functional operational equipment and overall design in the working environment.

It is believed that the working trajectories are realized in the limited space of the outpatient's office and the adjacent areas. Such movements in a limited space obtain the nature of pendulum (from one object to another and back). Such movements cause tension to the visual and motor analyzer and the equilibrium organ, and with its monotonous rhythm and often accelerated rate bring fatigue with their monotony.

The detailed specification of a given profession must be based on the volume and nature of the labour but also on physiological, psychological and sociological studies, enabling the building of a multiple-sided scientifically substantiated image of the specific medicinal speciality, its weight, degree of psychological loading and nervous and emotional tension, the sanitary and hygienic and the objective conditions of the environment.

At this stage, we focus on some of the components of the research complex. Having in mind the meaning which is given to attention in the treatment and diagnostic activity of the general practitioner, we need to track down the volume and speed of the processed non-specific information in the dynamics of the working process.

To this end, it is advisable to use corrective tables - 
the so-called Landolt rings (pinking washers). The program contains 1024 symbols. For each experiment $1 / 2$ of the program of the table - 512 symbols are applied (at the researcher's choice). The study is performed three times in a working day - before, during and at the end of the patient's visit. The rings have 8 possible directions of the interruption and the number of rings with different direction of interruption is the same in each line, but their sequence has been selected using random numbers. During the experiment, the studied person crosses out all rings with the same direction of interruption. The time necessary for the whole corrective task is reported (using a stopwatch), as well as the number of rings crossed out. Two types of errors are possible in work with the table - missing of rings which need to be crossed out, or crossing out a ring with a different direction. Studies show that the errors are mostly related to missing signals. In order to find out the actual signal, the studied person makes a choice from 8 alternatives and therefore the useful signal bears information equal to $\log 21 / 8=3$ bits $\mathrm{N}$ (where $\mathrm{N}$ is the actual quantity of the signals listed by the experimental person). The whole program includes 1536 bits of information for processing.

On the basis of the so offered methodology, the following indexes are outlined: productivity - the average time spent for the performance of the corrective program (512 signals); wrongly indicated signals/identified signals - due to lower differentiation skills; missed signals/relevant signals - (unprocessed non-specific) information due to lack of concentration, negligence, etc.

The sociological studies evidence that the GP receives individual primary sociological information about their health condition and the professional factors having an impact on it. The use of direct individual anonymous questionnaire is recommended. The subjective tool for the study of fatigue in the dynamics of the working day and week is also included, under a five-degree scale with a closed question. A kind of counterpoint of the indicated objective methods of studying the workload and the structure of the outpatient's visits (time measurements, coordination in the activity of the team, working postures and trajectories), appears to be the individual sociological information about the organization of the activity and the relationship with the patient in the general medical practice. Question of bioethical nature is also differentiated - confidentiality, informed consent, the truth, communication of bad news, management of the lack of self-confidence, empathy, style of communication within the patient.

For the purpose of assessment of the sanitary and hygienic conditions, the following main parameters of the environment are outlined:

A. Microclimatic factors:

a) air temperature;

b) air humidity;

c) air movement.

B. Air purity, of which:

1. gas content:

a) air oxidation;

b) concentration of carbon dioxide;

2. microbial pollution: a) total number of microorganisms;

b) number of pathogenic staphylococci;

c) number of á-hemolytic streptococci.

C. Noise level

D. Lighting:
a) natural light;
b) artificial ligit;
c) uniform distribution.

The methodology used for a complex sanitary and hygienic assessment shows the degree of observation or nonobservation of the rules and norms under all indexes of the working environment, contributing to the maintenance or lowering of the working capacity and ensuring the requirements for the conduct of the treatment and diagnostic process in the general medical practice.

\section{CONCLUSION.}

The organization and structure of the working process of the general practitioner are characterized by certain specifications. The complex and profoundly developed in an ergonomic aspect research complex of methodological approaches enables detailed analysis of the activity of the central figure in the primary medical aid - the general practitioner:

The developed methodological approaches for studying of the physician's labour regime and procurement of optimal physiological and objective conditions for their application are a reliable indicator of objective assessment of the quality of the activity in the general medical practice. The observation of the main criteria for efficient health service in the sphere of primary medical aid regulated in the medical standards appears to be the main precondition for the resolution of this strategic problem in our healthcare system.

They are studying the opinion of the general practitioners (by means of transversal sociological surveys) on the influence of the environmental factors on their health condition, the style of communication with the patient and coping with dilemmas of ethical nature, focusing on the need of adoption and application of psycho-social knowledge of the design of the working environment. Tracking down the processes of working capacity and coming fatigue (using objective and subjective tools) within the frameworks of the professional workload, proves to be an efficient controlling indicator and corrective for the optimization of the activity in the system of primary medical aid. The construction of a rational and flexible system for the performance of the so proposed methodological means of studying the dynamics of the working process and the introduction of an efficiency and intensity assessment coefficient in the general medical practice is an effective precondition for the timely elimination and overcoming of the deficiencies, contradictions and shortcomings with a view to ensuring and stimulating a highquality health aid in the practice of general medicine.

\section{Acknowledgement}

This work is supported by the Bulgarian Ministry of Education and Science under the National Program for Research "Young Scientists and Postdoctoral Students". 


\section{REFERENCES:}

1. [Ordinance No. 41 of 21 December 2005 on ratification of "Medical standards of general medical practice".] issued by the Minister of Health, published SG No: 1/3 January 2006, amended SG 101/28 December 2010, effective as of 1st January 2011, SG 49/ 28 June 2011, effective as of 28 June 2011. [in Bulgarian] [Internet]

2. Donabedian A. The Quality of Care: How Can It Be Assessed? JAMA. 1988;260(12):1743-48. [PubMed] [Crossref]

3. Medical Institutions Act, published SG 62/9 July 1999, suppl. SG 88/8 October 1999, amended SG 113/ 28 December 1999, corrected SG 114/ 30 December 1999, amended and supplemented SG 36/2 May 2000, SG 65/ 8 August 2000, effective as of 8 August 2000, SG 108/29 December 2000, effective as of 1 January 2001. [in Bulgarian] [Internet]

4. Stefanov R, Lyochkova M, Semerdzhieva M. [The patients' opinion regarding some quality aspects of the primary health aid in Plovdiv.] Praemedicus 2002; 1-2. [in Bulgarian]

5. Balashkova M, Valentinova Ts. [Patient-centered communication - reality or challenge for the General Practitioners.] [in Bulgarian] Scripta Scientifica Medica. 2011; 43(7):169-171.

6. Balashkova M, Goranov M. [Training of medical students in communication skills - perspectives and challenges.] [in Bulgarian] Collection of scientific reports from an Anniversary scientific conference of the Faculty of Medicine at the Thracian University of Stara Zagora. 2002; 2:25458.

7. Vekov T. The patients and medical doctors' satisfaction with the health care reform and recommendations for its management. Med. menidzh. $i z d r$. politika. 2008;39:19-26.

8. Petkov V. Satisfaction with the Quality of the Health Care after the Introduction of Mandatory Health Care in Bulgaria. Healthcare Management. 2004; 4(4):28-30.

9. Thompson M, Walter F. Increases in general practice workload in England. Lancet. 2016;387(10035):227072. [PubMed] [Crossref]

10. Weigel PA, Ullrich F, Shane DM, Mueller KJ. Variation in Primary Care Service Patterns by Rural-Urban Location. J Rural Health. 2016;32(2):196203. [PubMed] [Crossref]

11. Kitov B, Epifanceva E, Asenova R, Kitova T. Stress and its importance for the humanbody. General Medicine 2020; 22(6):74-80.

12. Popova NM, Tolmachev DA, Sysoev PG, Tyulkina EA. [The Application of the Technique Fotohronometra Observations in the Study of the Labor Process the Doctors of the Udmurt Republic.] [in Russian] Current problems of health care and medical statistics. 2015; 3:50-58. [Internet]

13. Vechorko VI. [Distribution of working hours of primary care physician with a nurse at a Moscow polyclinic (photo and time study).] [in Russian] Social aspects of public health. 2016; 52(6). [Crossref]

14. [Methods for developing time standards and medical staff workload.] [in Russian] Ministry of Health of the Russian Federation. 2013. p.28. [Internet]

15. Starodubov VI, Son IM, Ivanova MA, Armashevskaya OV, Lutsko VV, Sokolovskaya TA. [The time spent by specialist doctors on providing outpatient care.] Health Manger. 2016 (2), p. 6-12. [in Russian]

16. Hill AB. The Doctor's Day and Pay - Some Sampling Inquiries Into the Pre-War Status. J R Stat Soc Ser A Stat Soc. 1951; 114(1):1-34. [Crossref]

17. Eimerl TS, Pearson RJ. Workingtime in general practice. How general practitioners use their time. $\mathrm{Br}$ Med J. 1966 Dec 24; 2(5529):1549-54. [PubMed]

18. DANISH Medical Association. Br Med J. 1957; 2(5043):51516. [PubMed]

19. Faller H. [Shared decision making: an approach to strengthening patient participation in rehabilitation] [in German]. Rehabilitation (Stuttg). 2003 Jun;42(3):129-35. [PubMed]

20. Roter DL, Geller G, Bernhardt BA, Larson SM, Doksum T. Effects of obstetrician gender on communication and patient satisfaction. Obstet Gynecol. 1999 May 1;93(5):635-41. [PubMed]

21. Liochkova M. [The primary medical aid in the conditions of the health-insurance system - ethical criteria for its functioning.] In: Medical ethics, Medical Institute, Plovdiv. 1999. 61-67. [in Bulgarian]

22. Liochkova M, Semerdzhieva M, Stefanov R. [Problems of the Quality of Primary Health Care in Plovdiv] Scientific Research Project with Scientific Leader M. Lochkova, No. TKL-4, MUPlovdiv, MES, 2002. [in Bulgarian]

23. Kitova-John M, Tsigarovski G, Kitov B. Risk factors for the development of burnout syndrome by medical specialists. General Medicine 2020; 22(3): 73 - 79.

Please cite this article as: Alakidi A, Mihaylova V, Kilova K, Liochkova M, Shopov D. Methodological Approaches to Assessment of the Activity of the General Practitioner. J of IMAB. 2021 Jan-Mar;27(1):3604-3610.

DOI: https://doi.org/10.5272/jimab.2021271.3604

Received: 30/12/2019; Published online: 16/03/2021

Address for correspondence:

Adolf Alakidi, MD

Assistant Prof. Department of Hygiene, Ecomedicine and Nutrition, Faculty of Medicine, Medical University of Sofia, Bulgaria.

E-mail: delfi921@abv.bg 